\title{
Development of Supercapacitor-Aided Hybrid Energy Storage System to Enhance Battery Life Cycle of Electric Vehicles
}

\author{
Min-Fu Hsieh ${ }^{1}\left(\mathbb{D}\right.$, Po-Hsun Chen ${ }^{2}\left(\mathbb{D}\right.$, Fu-Sheng Pai ${ }^{3, *(\mathbb{D})}$ and Rui-Yang Weng ${ }^{1}$ \\ 1 Department of Electrical Engineering, National Cheng Kung University, Tainan 70101, Taiwan; \\ mfhsieh@mail.ncku.edu.tw (M.-F.H.); yangyang.weng@gmail.com (R.-Y.W.) \\ 2 Department of Applied Science, R.O.C. Naval Academy, Kaohsiung 81345, Taiwan; c0931602@gmail.com \\ 3 Department of Electrical Engineering, National University of Tainan, Tainan 70005, Taiwan \\ * Correspondence: fspai@mail.nutn.edu.tw
}

Citation: Hsieh, M.-F.; Chen, P.-H.; Pai, F.-S.; Weng, R.-Y. Development of Supercapacitor-Aided Hybrid Energy Storage System to Enhance Battery Life Cycle of Electric Vehicles. Sustainability 2021, 13, 7682. https:// doi.org/10.3390/su13147682

Academic Editors: Yu-En Wu and Chun-An Cheng

Received: 1 June 2021

Accepted: 5 July 2021

Published: 9 July 2021

Publisher's Note: MDPI stays neutral with regard to jurisdictional claims in published maps and institutional affiliations.

Copyright: (c) 2021 by the authors. Licensee MDPI, Basel, Switzerland. This article is an open access article distributed under the terms and conditions of the Creative Commons Attribution (CC BY) license (https:// creativecommons.org/licenses/by/ $4.0 /)$.

\begin{abstract}
This paper presents a C-rate control method for a battery/supercapacitor (SC) hybrid energy storage system (HESS) to enhance the life cycle of the battery in electric vehicles (EVs). The proposed HESS provides satisfactory power for dynamic movements of EVs (e.g., acceleration or braking) while keeping the battery current within a secure level to prevent it from degradation. The configurations of conventional HESSs are often complex due to the two energy storages and their current/voltage sensing involved. Therefore, in this paper, a simple current-sensing scheme is utilized and the battery is directly treated as a controlled variable to help the battery output current remain stable for different load conditions. While the proposed circuit requires only one current feedback signal, neither the SC nor load current sensors are needed, and the circuit design is thus significantly simplified. Both simulation and experimental results validated the effectiveness of the proposed HESS operating in conjunction with the motor drive system. The proposed method aims at fully utilizing recycled energy and prolonging battery lifespan.
\end{abstract}

Keywords: hybrid energy storage system (HESS); C-rate control; electric vehicles (EVs); supercapacitor (SC); battery lifetime

\section{Introduction}

Energy storage systems are critical for electric vehicle technology and are typically constructed based on lithium-ion batteries. Lithium-ion batteries are widely adopted because of their high energy density, low self-discharge rate, and being free from the memory-effect property. Despite these advantages, battery-based energy storage systems face some technical barriers, such as high cost and difficulty in controlling the battery system. Frequent battery charge and discharge significantly reduce the battery life cycle, leading to high maintenance costs. Furthermore, lithium-ion batteries are sensitive to temperature. Under heavy load conditions, the temperature of the battery pack may rise rapidly and result in internal resistance transformation and capacity fading over the long term [1-4]. To overcome these drawbacks, supercapacitors (SCs) have become a popular choice as an aid [5-8]. Although the energy density of SCs is lower than that of batteries, the power density of the SC is higher, which means that the SC can be charged or discharged frequently and rapidly with a larger current. As a result, studies on traction motor drive systems and on HESSs with batteries and an SC are of much importance recently.

In response to the necessity of HESS development, optimal sizing for an HESS by optimizing the life cycle and size reduction has been previously presented [9-12]. The component sizing of the HESS and an energy management strategy (EMS) based on heuristic rule-based control and dynamic programming was proposed [9], where an improvement in fuel economy from $5 \%$ to $15 \%$ was obtained for a mild hybrid powertrain. In the work by Zhang et al. [10], the effect of supercapacitor sizing on temperature rise, capacity loss, and power fading was presented. Eldeeb et al. [11] proposed the optimal sizing of the HESS 
based on the multi-objective optimization for plug-in hybrid electric vehicles (PHEVs). The wavelet transform method was adopted and the cut-off frequency was selected based on the sampling frequency and the number of data points in the sampled signals. The optimization problem was solved by using a genetic algorithm. Asensio et al. [12] developed the optimal sizing of a semi-active HESS based on the cut-off frequency for the filter. In addition, some literature has provided various solutions for optimal circuit configurations capable of predicting battery and electric motor performance.

Several multiple-input HESS configurations with parallel/series converters have been widely discussed, where the battery/SC charge and discharge can both be achieved [13-16]. The passive HESS topology is simple and has no need to increase the cost of electronic devices. However, the stability of the system is low, and the output power of battery and SC devices cannot be well controlled. While the fully-active HESS topology possesses advantages of high flexibility, improved performance, and extended cycle life, its cost and complexity are also high, and thus the applications are limited. Therefore, the semiactive structure should be an appropriate choice for the HESS system to achieve a flexible design based on the purpose of applications. A qualitative comparison based on various HESS strategies in EV applications is presented in Table 1. A previous study proposed a battery-SC HESS to store the recovery braking energy using a dual-source bidirectional converter [13], where the battery and the SC are connected only through a power switch. Nevertheless, this circuit scheme may result in serious variation in battery current, which may shorten its lifetime. In [14], a strategy that reassigns the uncompensated power from the battery to the SC is suggested for HESS integration by multiple parallel converters. This method contributes to faster DC link voltage restoration. Other advanced control strategies have been recently studied for HESSs, including the model predictive control, which features online optimization, fast dynamic response, and easy constraint incorporation $[15,16]$. However, the predictive control-based methods with whole-system state-space models require a large number of multiplication steps, thereby complicating the circuits and system design as a whole $[17,18]$.

Table 1. Qualitative comparisons of various HESS structures.

\begin{tabular}{|c|c|c|}
\hline \multicolumn{2}{|c|}{ HESS Structure } & \multirow[b]{2}{*}{$\begin{array}{l}\text { Simple structure } \\
\text { Low cost of required device }\end{array}$} \\
\hline Dosoinz & Pros & \\
\hline 1 asoive & Cons & $\begin{array}{l}\text { Unstable system voltage } \\
\text { Uncontrollable power distribution }\end{array}$ \\
\hline \multirow{2}{*}{ Semi-active } & Pros & $\begin{array}{l}\text { Flexible system configuration } \\
\text { Lower cost of devices }\end{array}$ \\
\hline & Cons & $\begin{array}{l}\text { Caution needed in stability of system voltage } \\
\text { Higher requirement for DC-DC converter }\end{array}$ \\
\hline \multirow{2}{*}{ Active } & Pros & $\begin{array}{l}\text { High system flexibility } \\
\text { High system efficiency }\end{array}$ \\
\hline & Cons & $\begin{array}{l}\text { High cost of system and related devices } \\
\text { Efficiency affected by DC-DC converter }\end{array}$ \\
\hline
\end{tabular}

Note that conventional methods mainly employ a voltage controller in the DC-DC converter for control of the output voltage of the SC, which can only indirectly control its output current $[11,19]$. Thus, it would be difficult to achieve the required C-rate control for an HESS. However, by using current control as proposed in this paper, the battery current can be dynamically adjusted. Therefore, in this paper, a C-rate control method for a battery/SC HESS is proposed to satisfy various operating conditions for electric vehicle (EV) applications and achieve the purpose of life cycle extension.

The C-rate is defined as the charging or discharging current divided by the battery capacity. With the approach proposed in this paper, the HESS provides sufficient power for 
motor startup and acceleration periods, while the impact of violent vehicle movements on the potential degradation of battery capacity can be mitigated. In addition, a pulse-width modulation (PWM) control method associated with a simplified current-sensing scheme is developed, where the current transformer (CT) is installed in the battery branch as the current feedback to the controller of the DC-DC converter in order to control and monitor the deviation of battery current. By so doing, the nodal current of the battery is directly treated as a controlled variable, and this helps stabilize the battery output current and satisfy various load conditions. Therefore, comparing with previous studies [11,19], the proposed circuit design not only possesses a simple structure (i.e., with a simplified current-sensing method) but also owns a high capability to enhance the battery life cycle (i.e., directly controlling the battery C-rate) for EV applications. The proposed method is validated by both simulation and experiment on a motor driving circuit to meet the requirements of EVs with an increase of battery lifespan.

The organization of this paper is as follows. Section 2 describes the operational principle of the proposed HESS. Section 3 gives the paradigm of the C-rate control system, and Section 4 is the simulation results with an ECE 40 driving cycle. The test results are presented in Section 5, followed by Section 6 which draws the conclusions.

\section{System Configuration and Operation}

Figure 1 illustrates a schematic diagram of the proposed HESS, where the system is composed of a battery pack, an SC pack, a bidirectional DC-DC converter, an inverter, and an interior permanent magnet synchronous motor (IPMSM). The HESS connects the battery with the SC by the DC-DC converter. Then, the battery and inverter are cascaded to power the motor. In this system, the voltage across the SC allows it to be charged within a range due to the duty control of the DC-DC converter such that the energy storage in the SC can be utilized. In the block diagram shown in Figure 1, the controller of the DC-DC converter is mainly composed of a current loop designed to offer the switching signals for the C-rate control of the battery current. The controllers of the inverter mainly employ the direct-axis (d-axis) and quadrature-axis (q-axis) current loops to generate the required $\mathrm{d}$-q-axis current commands for torque and speed control. The $\mathrm{d}$-q-axis commands are then transformed into the $\alpha$ - $\beta$-axis domain for space vector pulse-width modulation (SVPWM) of the inverter.

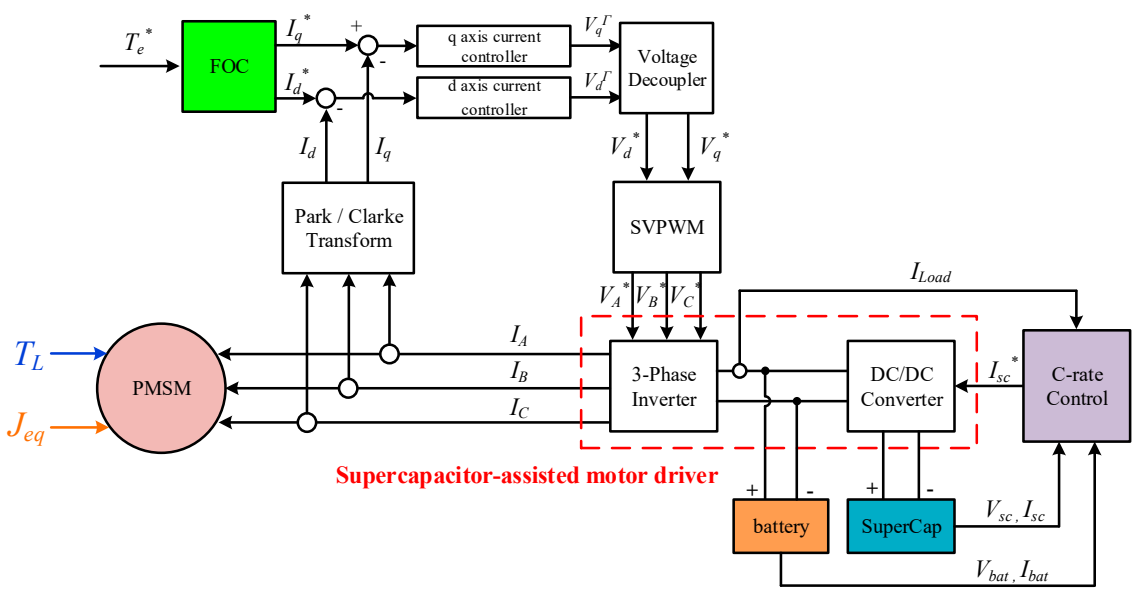

Figure 1. Proposed HESS for IPMSM drive.

In the proposed system, the DC-DC converter and inverter are the bridge between the energy storage elements and motor, which are able to distribute the energy flow by switching the power switches inside the HESS. This is explained as follows.

Case 1: Vehicle in the constant speed mode

In the constant speed mode operation, the motor requires only a small current to maintain the speed. The battery is efficiently utilized under this condition to provide an 
all-load current. The DC-DC converter is turned off to prevent the overall system from efficiency deterioration due to the operational losses of the converter. The power flow in this case is indicated in Figure 2a.

(a)

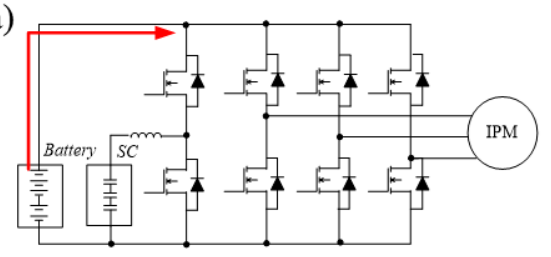

(c)

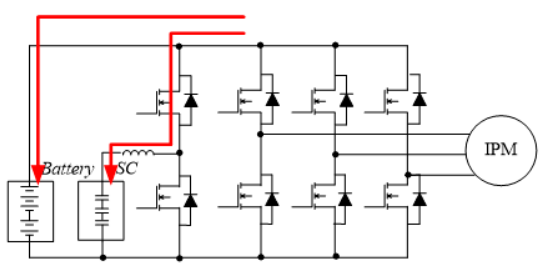

(b)

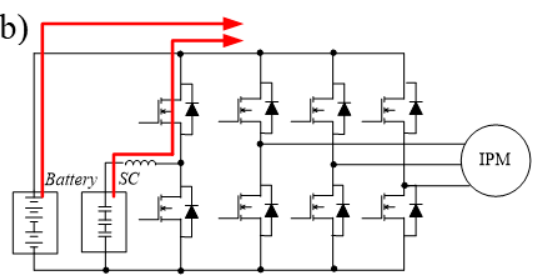

(d)

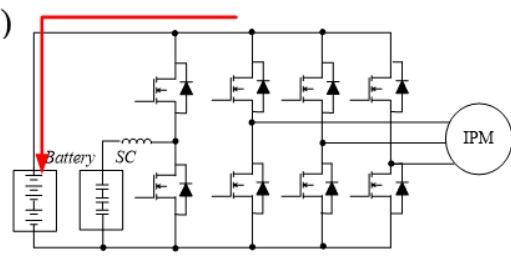

Figure 2. Power flow of proposed HESS under different vehicle operations. (a) Motor constant speed; (b) Motor acceleration; (c) Motor regenerative braking (1); (d) Motor regenerative braking (2).

Case 2: Vehicle in the acceleration mode

In the acceleration mode, the SC is boosted to the DC-bus voltage through the DC-DC converter, and then the battery and SC are combined to provide the power required by the vehicle. The power flow in this case is shown in Figure $2 \mathrm{~b}$. When the SC voltage reaches the low voltage limit and low energy storage, all the output energy is provided by the battery as in Case 1.

Case 3: Vehicle in the regenerative braking mode

In the regenerative braking mode, the kinetic energy of the vehicle is converted and recharged back to the HESS. In this mode, as shown in Figure 2c, if the SC works normally, the regenerative energy of the motor is stored in the SC through the control of the DC-DC converter to prevent the battery module from rapid charge by the regenerative pulse power and potential damage that would shorten the battery lifespan. However, as in Case 2, when the SC touches the voltage limit with low stored energy, all the recovered energy is absorbed by the battery, as shown in Figure 2d.

\section{Proposed C-Rate Control Scheme}

\subsection{Capacity Characteristics Analysis of Lithium-Ion Battery under Cyclic Charge/Discharge}

As previously mentioned, a battery-based HESS for motor drives faces the challenges of battery lifespan. This results from the fact that the rapid changes in the speed and torque demands of a vehicle cause the battery to charge and discharge rapidly and frequently. The maximum storage capacity of a battery may decrease as its charge/discharge cycles increase. Thus, C-rate is an important factor in battery operation considering lifespan. Mostly, when the battery capacity declines to less than $80 \%$ of its initial capacity, the pace of aging becomes faster. Thus, the storage capacitor of the battery can be used as a baseline for the degree of battery aging [7].

To further investigate the effect of discharging current on battery lifespan, different C-rate discharges for the lithium-iron phosphate battery were conducted by battery models in Simulink ${ }^{\circledR}$ simulation, where a composite battery pack of $48 \mathrm{~V}$ and $12 \mathrm{Ah}(1 \mathrm{C})$ was simulated. At the beginning of the test process, the battery voltage was calculated to confirm that it had reached fully charged voltage. If the voltage was less than the fully charged value, the battery was charged at $6 \mathrm{~A}(0.5 \mathrm{C})$ to achieve full capacity. After being fully charged, the discharging process of the battery was executed. In this case, the performance of the discharging process was validated under different discharging 
currents within 1 to 5 C-rates. Figure 3 shows the capacity curves of the lithium-ion battery obtained by 2000 cycles of battery charge and discharge. The capacity exhibits a clear decrease following the increase in the number of discharge cycles. However, there are still differences for different $\mathrm{C}$-rates. The capacity of the battery discharged at $1 \mathrm{C}$ is reduced to 11.21 A at the end of the test, while the capacity of the battery discharged at $5 \mathrm{C}$ is reduced to $10.65 \mathrm{~A}$. The results confirm that the greater the battery discharge current, the faster the capacity degradation.

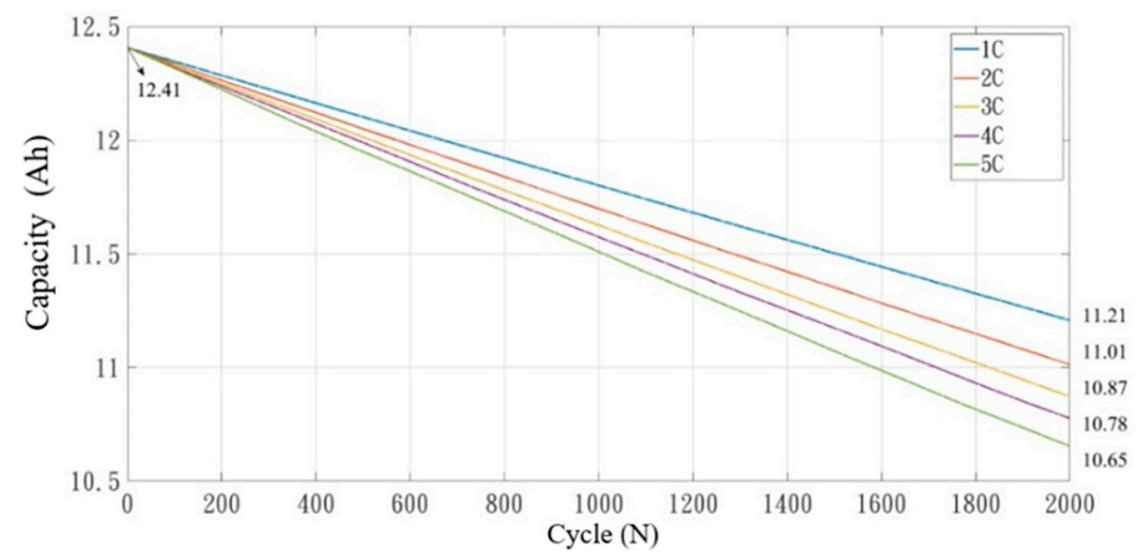

Figure 3. Simulated capacity curves of a lithium-ion battery during cycling with different discharge current.

\subsection{Proposed C-Rate Control Method}

To mitigate the possible capacity degradation, a proposed C-rate control method corresponding to the HESS shown in Figure 1 for the IPMSM drive is developed. This C-rate control method generates the current command of the DC-DC converter according to different operating modes of the vehicle and the SC voltage status. In this proposed method, the battery voltage, SC voltage, and motor speed are detected and compared with a speed threshold. When the speed deviation is greater than the pre-determined threshold, the system runs in the acceleration mode. In this mode, a large current is required to obtain high torque. Both the battery and SC are thus used to deliver sufficient current to the loads. In this case, the current dispatch from each energy source is based on the predefined C-rate limit of the battery. When the load current exceeds the permitted current value of the battery, the SC outputs the current difference between the battery supply and load requirement to avoid over-discharge. In addition, when the motor is operated in the regenerative braking mode, the ideal circuit configuration is when the reduced kinetic energy is converted into electrical energy and stored in the SC. In this case, the SC voltage is checked again to confirm the usability of the SC energy sink. If the SC voltage is lower than the highest operating voltage of the SC, the DC-DC converter is activated in the step-down mode to control the energy transfer from the motor braking to the SC. At this time, the $\mathrm{SC}$ voltage rises. In contrast, the generated energy by the motor is fed into the battery for temporary storage.

To realize the C-rate control method, Figure 4 plots the PWM controller of the DCDC converter in the proposed HESS. As can be seen, the desired control command is determined by the current reference selector. In the acceleration mode, when the battery current is higher than the predefined level, the predefined C-rate value is selected as the current reference $i_{\text {bref }}$. Then, in the regenerative braking mode, $i_{\text {bref }}$ is set at zero. In this case, the battery current is traced to zero via the effort of the DC-DC converter. It implies that all the regenerative breaking current flows into the SC through the DC-DC converter. After $i_{\text {bref }}$ is determined, a current regulator is employed to regulate the error between the desired and actual battery current $i_{b f b}$. The signal transmission of the regulator output to the PWM modulator can then be performed to offer the required switching signals for the semiconductor switches. 
(a)

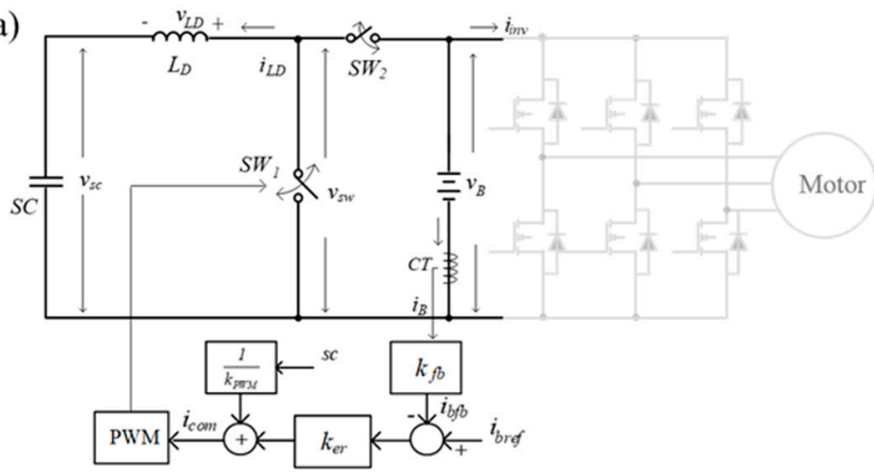

(b)



Figure 4. (a) A simplified DC-DC converter circuit. (b) Switching period of PWM in the DCDC converter.

For the current feedback control scheme shown in Figure 4a, a current loop with an error amplifier of the gain $k_{e r}$ is developed by comparing the reference current signal $i_{b r e f}$ and the feedback signal obtained from the current sensor. In addition, a feedforward subloop of the capacitor voltage signal $v_{s c}$ is designated for mitigating the undesirable effects of possible voltage variations to the SC. The resultant PWM signal $i_{\text {com }}$ is formulated as below:

$$
i_{c o m}=\left(i_{b r e f}-k_{f b} i_{B}\right) \times k_{e r}+\frac{1}{k_{p w m}} v_{S C}
$$

where $k_{f b}$ is the gain of the current transformer $(\mathrm{CT}), k_{p w m}$ is the PWM gain, $i_{B}$ is the battery current, and $v_{s c}$ is the terminal voltage of the SC. Next, following the circuit configuration shown in Figure $4 \mathrm{a}$, the inductor current $i_{L D}$ can be expressed in terms of battery current $i_{B}$ and input current of the inverter.

$$
i_{L D}=i_{B}-i_{I N V}
$$

Then, with the Laplace transform operation, Equation (2) can be written as:

$$
s L_{D} i_{L D}=v_{S W}-v_{S C}
$$

where " $s$ " is the Laplace operator, and $L_{D}$ and $v_{S W}$ are the inductor and the switch voltages in the DC-DC converter, respectively. When the signal transmission of the current regulator $i_{\text {com }}$ output to the PWM is performed to offer the required switching signal for the semiconductor switch SW1, the voltage output of the PWM can be calculated by the average voltage during a switching period as:

$$
v_{S W}=\left(S W F \times v_{B}\right)_{a v}
$$

where SWF is the switching function of the main semiconductor switch at the DC-DC converter and is defined as:

$$
S W F= \begin{cases}1 & \text { if switch } S W_{1} \text { is off } \\ 0 & \text { if switch } S W_{1} \text { is on }\end{cases}
$$


Note that Equation (5) is a time-variant and non-linear expression, and an approach such as small-signal linearization can be employed. The parameter of $i_{\text {com }}$ should be within a small area of variation based on the fed back $v_{S C}$ and $i_{B}$. If $i_{c o m}$ can be assumed constant within a period of ramp waveform in the expression of the waveforms in Figure $4 b$, the average of SWF during a switching PWM period can be calculated as follows:

$$
(S W F)_{a v}=\frac{\int_{0}^{\left(t_{1}+t_{2}\right)} S W F d t}{t_{1}+t_{2}}=\frac{i_{c o m}}{v_{r a m p}}
$$

Substituting Equation (6) into Equation (4) yields

$$
v_{S W F}=\frac{i_{c o m}}{v_{\text {ramp }}} V_{B}
$$

Therefore, the gain $k_{p w m}$ can be derived to be:

$$
k_{P W M}=\frac{v_{B}}{i_{\text {com }}}=\frac{v_{B}}{v_{\text {ramp }}}
$$

By rearranging Equations (1), (3), and (8), the following equation can be obtained:

$$
i_{B}=\frac{k_{e r} k_{p w m}}{\Delta} i_{b r e f}-\frac{s L_{D}}{\Delta} i_{I N V}
$$

where $\Delta=s L_{D}+k_{f b} k_{e r} k_{\text {pwm }}$. Thus, the following transfer function can be obtained:

$$
H_{I}(s)=\frac{i_{B}}{i_{b r e f}}=\frac{k_{e r} k_{p w m}}{s L_{D}+k_{f b} k_{e r} k_{p w m}}
$$

In Equation (10), the control bandwidth of the system can be derived from the characteristics equation of the denominator. Meanwhile, the bandwidth is affected mainly by the current loop gain $k_{e r}$. This implies that by properly setting $k_{e r}$, the current loop would be able to drive the feedback signal toward the corresponding reference signal with the $\mathrm{C}$-rate control mode.

It is also worth mentioning that in most operating strategies of the HESS, the DCDC converter mainly acts to solve the short-term power demand variations and power sharing between the SC and the battery, where the SC responds to the high-frequency power exchange through the inner current control loop. In these cases, the CTs for the PWM control are installed at both SC and inverter input branches. Then, the desired current command is obtained from the steps of signal analyses and the calculations of the nodal current of the SC as well as the inverter input. This leads to possible delays in the converter's response. In the proposed method, the actual battery current $i_{b f b}$ is obtained by the CT feedback, which is installed at the battery branch rather than the SC or inverter side. By using this method, the current regulator could directly drive the battery current at a lower or equal to the predefined C-rate value, and the required current command in the DC-DC controller is not necessary to calculate in advance. The computation procedure and circuit designs are, therefore, relatively easy to accomplish. Related simulation and experimental tests are conducted as presented in the following sections to verify the effectiveness of the proposed HESS circuit.

\section{Simulation Study with ECE 40 Driving Cycle}

To validate the effectiveness of the proposed circuit and control method, different scenarios are examined in this study. Figure 1 is the schematic diagram used for the buildup of the simulation. The parameters for the tested system are listed in Table 2. They include the rated battery voltage and capacity of $48 \mathrm{~V}$ and $11.2 \mathrm{Ah}$, respectively. The SC pack is $38 \mathrm{~V} / 40 \mathrm{~F}$. The armature resistance of the IPMSM is $27 \mathrm{~m} \Omega$. The $\mathrm{d}$ - 
axis and q-axis inductances are 308 and $362 \mu \mathrm{H}$, respectively. The rated speed, torque, and power of the motor are $3000 \mathrm{rpm}, 7 \mathrm{Nm}$, and $2000 \mathrm{~W}$, respectively. The inverter is operated at the switching frequency of $20 \mathrm{kHz}$. In the simulation, Simulink ${ }^{\circledR}$ is used to investigate the dynamic behaviors of the $\mathrm{DC}-\mathrm{DC}$ converter and inverter controller and emulate the FOC operation for the PMSM. An ECE40 driving cycle [20,21] is then used to evaluate the current responses of the proposed HESS. The standard testing steps of ECE40 include three periods for acceleration, deceleration, and constant speed testing [20,21]. The total operation time for one cycle is $195 \mathrm{~s}$. The maximum vehicle speed is $50 \mathrm{~km} / \mathrm{h}$. Figure 5 shows the motor speed command under the ECE40 driving cycle. As shown in the figure, the proposed controller allows the vehicle to track the demanded speed well, which indicates that the test data were convincible. In addition, the simulation results also show the maximum load current of around $10 \mathrm{~A}$. Therefore, the battery current limit in this test is set to $4 \mathrm{~A}$, and the excess amount is compensated for by the SC. Based on these testing scenarios, the results of each test are described below.

Table 2. Parameters of simulation study.

\begin{tabular}{lc}
\hline & HESS Parameters \\
\hline Rated Battery Voltage & $48 \mathrm{~V}$ \\
Battery Capacity & $11.2 \mathrm{Ah}$ \\
Supercapacitor & $40 \mathrm{~F} / 38 \mathrm{~V}$ \\
Converter Switching Frequency & $20 \mathrm{KHz}$ \\
Inductor L & $130 \mathrm{MH}$ \\
Converter Rated Power & $2000 \mathrm{~W}$ \\
\hline & \\
\hline Armature resistance $\mathrm{R}_{\mathrm{s}}$ & PMSM Parameters \\
Direct-axis inductance $\mathrm{L}_{\mathrm{d}}$ & $27 \mathrm{~m} \Omega$ \\
Quadrature-axis inductance $\mathrm{L}_{\mathrm{q}}$ & $308 \mu \mathrm{H}$ \\
Rotor flux linkage $\lambda$ & $362 \mu \mathrm{H}$ \\
Pole pair P & $0.0128 \mathrm{~Wb}$ \\
Rated speed $\mathrm{V}_{\mathrm{m}}$ & 4 \\
Rated torque $\mathrm{T}_{\mathrm{m}}$ & $3000 \mathrm{rpm}$ \\
Rated power $\mathrm{P}_{\mathrm{m}}$ & $7 \mathrm{Nm}$ \\
Switching frequency of inverter & $2000 \mathrm{~W}$ \\
\hline
\end{tabular}

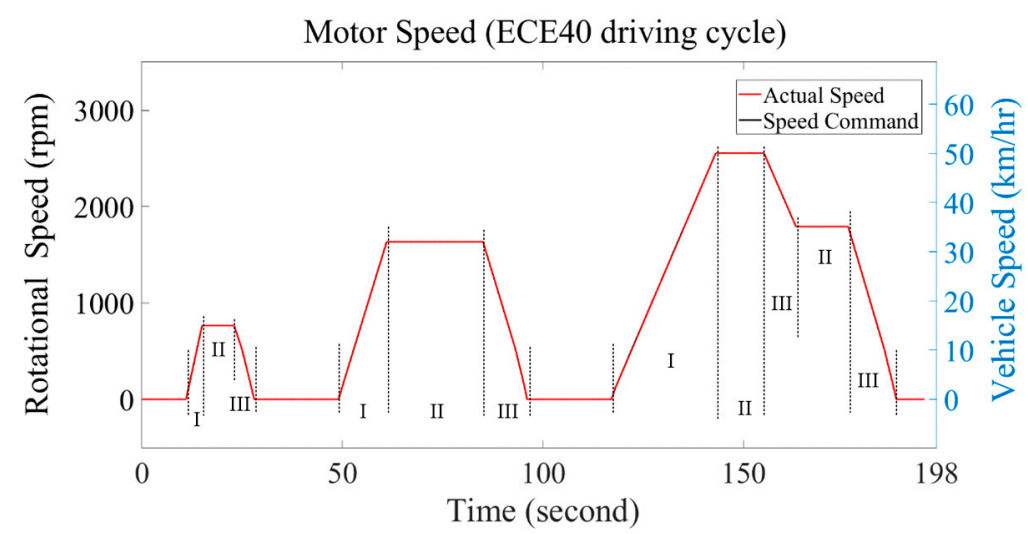

Figure 5. Motor speed under ECE40 driving cycle. (I: Acceleration, II: Constant speed, III: Braking duration).

According to Figures 5 and 6, the vehicle is initially in the ready mode and idle status. During the acceleration period, the accelerator (marked as "I" in Figure 5) signal rises to provide more torque (power). The higher the demanded power is, the larger the motor current value will be. Thus, the load current is higher than the set value of the battery current limit for a short time. At this time, the SC fills the load current gap between the 
demand current and the battery current $(4 \mathrm{~A})$ through the DC-DC converter. The average output current of the battery is then maintained at $4 \mathrm{~A}$ to avoid the high pulse current output affecting the battery lifecycle.

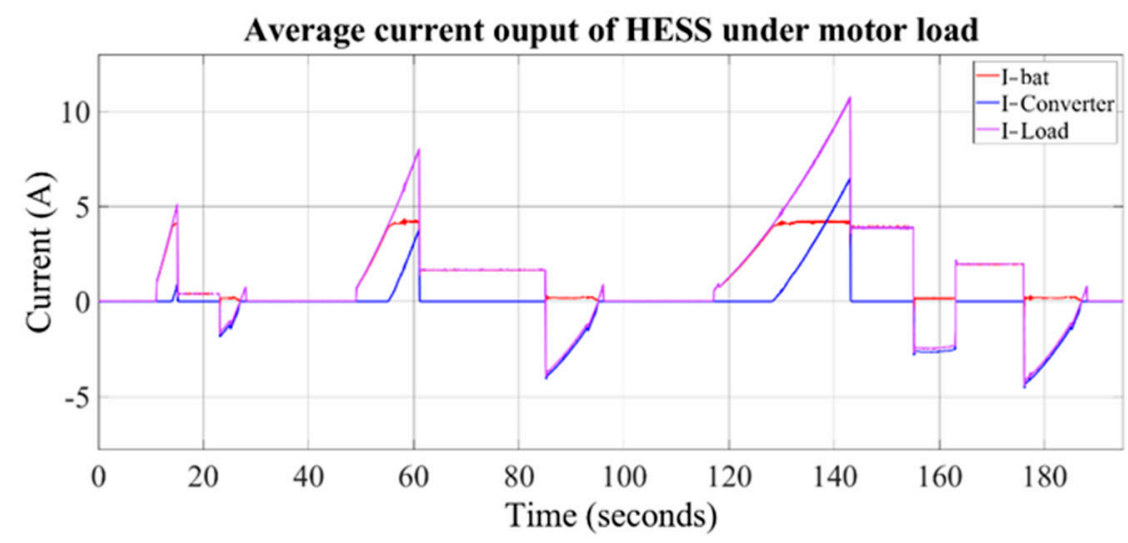

Figure 6. Average current output under ECE40 driving cycle.

Next, the mode was quickly switched to a constant speed period, where the required current from the load is not high, and therefore the influence on battery lifespan should not be a major concern; thus, only the battery module of the HESS is used for powering the motor load. In the deceleration mode, the kinetic energy stored in the vehicle will be recycled to the HESS via the motor that works in regenerative braking. It is known that the battery should not be recharged with a large amount of energy in a short instant in order to protect the battery without shortening its lifespan. In addition, to ensure the SC has sufficient energy for acceleration during the vehicle operation, the proposed HESS is designed to store all of the recharged energy to the SC preferentially.

In addition, this paper simulates the decline of the maximum capacity of the lithiumion battery by repeating the ECE40 driving cycle until one full year. Using the pure batterypowered electric motorbike configuration, the capacity of the lithium battery declined from 12.41 Ah to 11.61 Ah after one year, as shown with an orange curve in Figure 7. With the proposed SC-assisted hybrid motor drive, the lithium battery capacity only declined to 11.9 Ah for the same cycles of operations. Therefore, using the proposed HESS can reduce the battery life loss by $2.34 \%$ a year. With the curve in Figure 3, it can be deduced that the lithium battery lifespan is extended by around one and a half years.

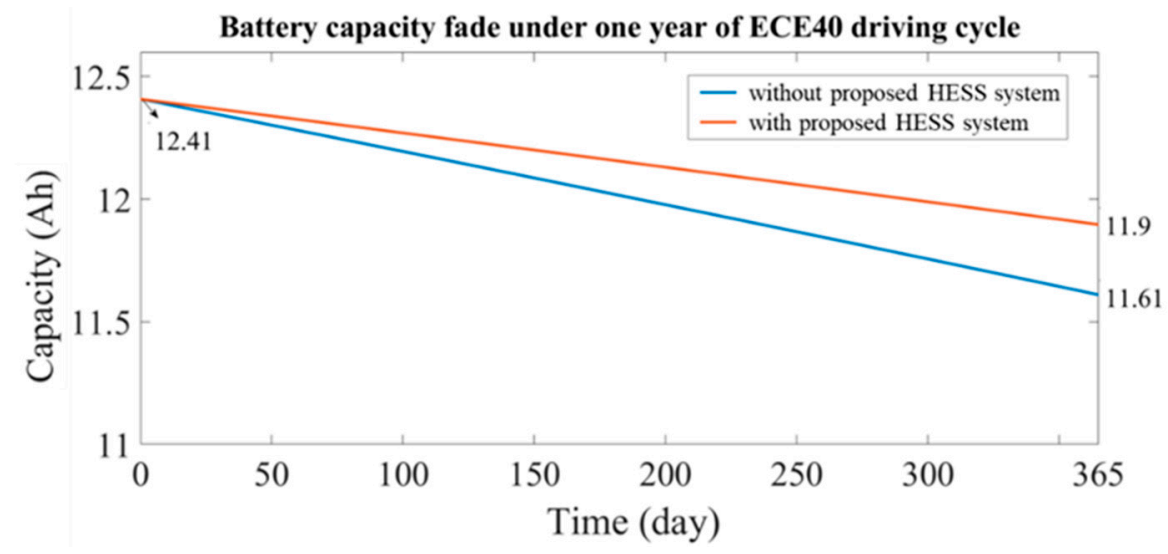

Figure 7. Battery capacity fade under one year of ECE40 driving cycle.

Simulations using hardware-in-the-loop (HIL) were conducted to verify the motor performance under low battery voltage. As shown in Figure 8, the HIL test results show that no matter what the battery condition is (i.e., at low voltage $42 \mathrm{~V}$, rated voltage $48 \mathrm{~V}$, and 
high voltage $52 \mathrm{~V}$ ), the motor can be smoothly driven at the rated speed of $2000 \mathrm{rpm}$ and a torque of $7 \mathrm{~N}-\mathrm{m}$ with sine wave currents. Nevertheless, in the condition of low battery voltage, the FOC current control command may approach saturation, which will make the switching duty cycle calculated by SVPWM approach the maximum limit to the numerical scale of the control program, leading to a larger motor torque ripple. The HIL simulation results also show that the torque ripple of the motor driven by $42 \mathrm{~V}$ is $3.7 \%$, which is about twice that for $48 \mathrm{~V}(1.57 \%)$. This should not be desirable for EV applications but is still within acceptable specifications. It should be noted that the SC is primarily to assist the battery in dynamic operation and to keep the battery current below a prescribed limit, instead of compensating the power needed in steady-state operation. The introduction to the HIL tool kit used here has been reported in [22] and will be repeated.

(a) $42 \mathrm{~V}$

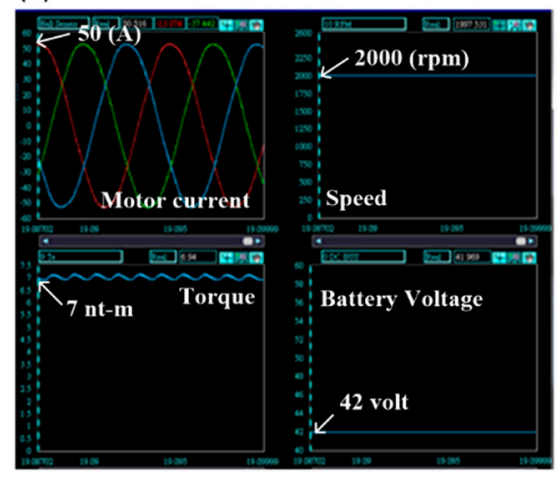

(b) $48 \mathrm{~V}$

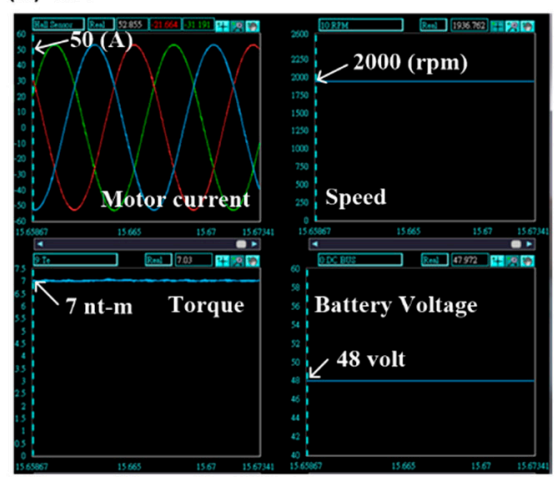

(c) $52 \mathrm{~V}$

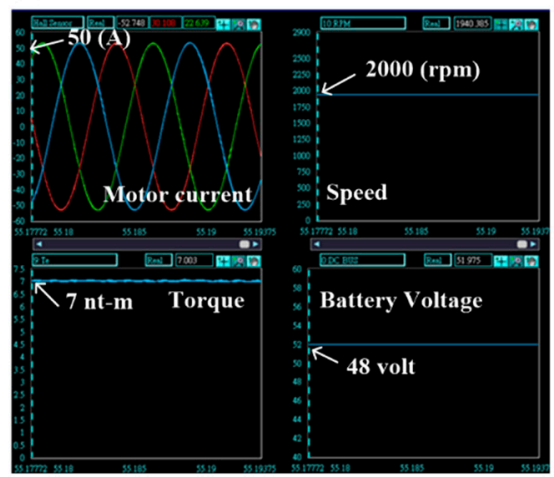

Figure 8. Simulation results for various voltages of the motor with (a) low voltage $42 \mathrm{~V}$, (b) rated voltage $48 \mathrm{~V}$, and (c) high voltage $52 \mathrm{~V}$.

\section{Experimental Results}

In this study, a $2 \mathrm{~kW}$ PMSM, drive, and the HESS were implemented and tested in the laboratory. Figure 9 presents the prototype HESS and motor drive. Figure 10 delineates the experimental voltage and current outcome of both the battery and SC in which the load current is set lower than the permitted battery current. As shown in Figure 10, the testing load current is only $3 \mathrm{~A}$, which is lower than the preset of the battery current $4 \mathrm{~A}$. The battery is able to deliver all the current needed for the load. The DC-DC converter is thus turned off, and the energy storage in the SC is reserved. In Figure 11, the system response for the higher load current case is examined, where the battery current is seen kept almost at the permitted value of $4 \mathrm{~A}$, even when the load current suddenly increases and is largely greater than the permitted battery current. This outcome indicates that, with the proposed circuit scheme and control method, the battery operation can be less impacted by such a pulse current, thus supporting the robustness of the method under the battery aging scenario considered.

(a)



(b)

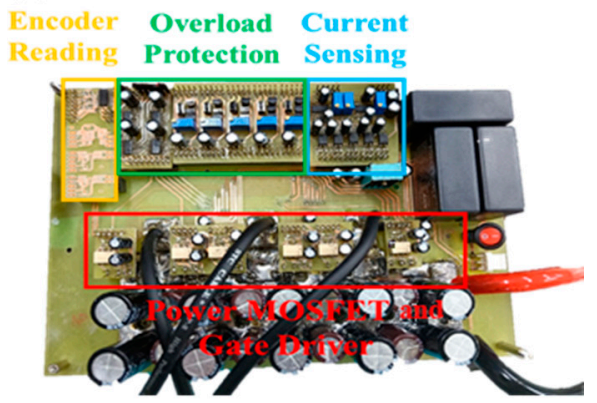

Figure 9. Laboratory prototype (a) proposed HESS (b) motor drive circuit. 
(a)



(b)

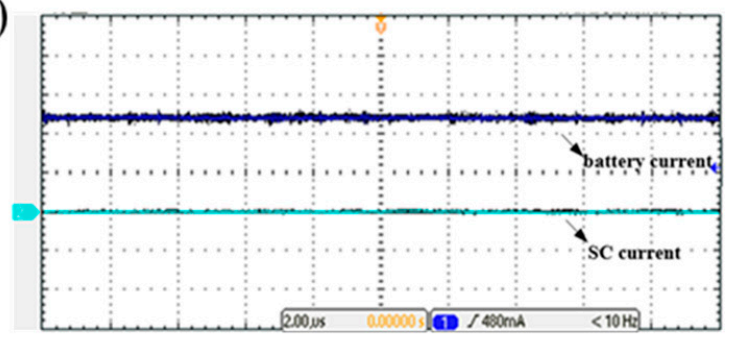

Figure 10. Voltage and current waveforms of proposed HESS when load current is (a) lower and (b) higher than permitted battery current. (current: $1 \mathrm{~A} /$ div, voltage:10 V/div, time: 2 us).

(a)

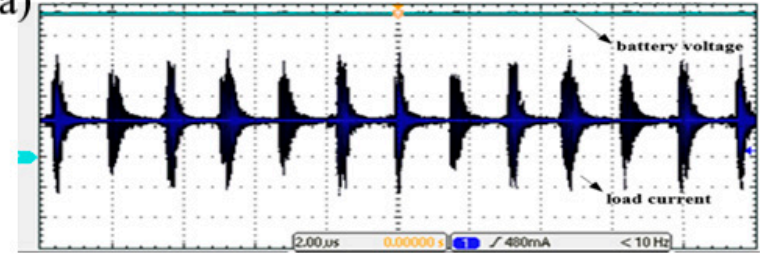

(b)

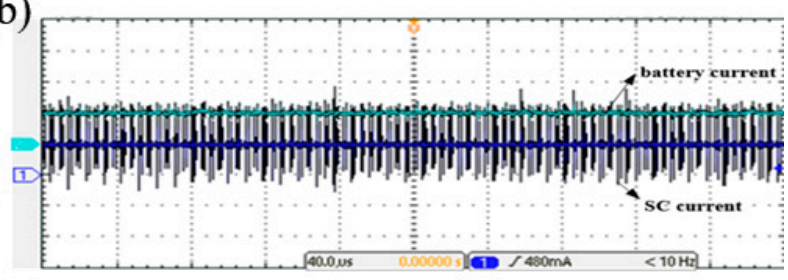

Figure 11. Voltage and current waveforms of proposed HESS when load current is higher than permitted battery current. (a) Battery voltage and load current waveforms (current: $4 \mathrm{~A} /$ div, voltage: $10 \mathrm{~V} /$ div, time: 2 us); (b) Battery and SC current waveforms (current: $4 \mathrm{~A} / \mathrm{div}$, time: $40 \mathrm{us}$ ).

Next, a test was performed to investigate the circuit efficiency under different power conditions. Figures 12 and 13 show the waveforms for the voltage $V_{D S}$ of the upper and lower arms and the inductor current for the proposed DC-DC converter in the step-up and step-down modes, respectively. In the figures, the drain-source voltage waveforms of the power switches exhibit some voltage spikes due to stray inductance and capacitance in the circuit. Yet, the current waveform of the inductor is not affected, as the upper chart indicates a linear change and a continuous conduction mode (CCM) operation, hence maintaining the supplying power quality of the HESS. In these tests, the operational efficiency is also measured. Table 3 tabulates the efficiency measurement for different power and operating modes. The circuit efficiency for the boost mode is $94.7 \%$ with a $544.6 \mathrm{~W}$ output, $93.5 \%$ with 1066.2 W, and $91.1 \%$ with $1903.9 \mathrm{~W}$. For the step-down mode, they are $96.3 \%, 95.7 \%$, and $93.9 \%$ for $464.5 \mathrm{~W}, 1160.7 \mathrm{~W}$, and $2031 \mathrm{~W}$, respectively. From the list in Table 3, the efficiency of the circuit operation is deemed satisfactory. Note that the resultant large heat and power losses for the traditional two-stage power conversions may degrade the energy conversion efficiency of the whole system. However, in the proposed HESS, the DC-DC converter is only turned on in the acceleration and braking mode. With shorter operation time and higher efficiency of the DC-DC converter operation, the proposed HESS can operate in an optimal state to increase efficiency and extend battery lifetime.

(a)

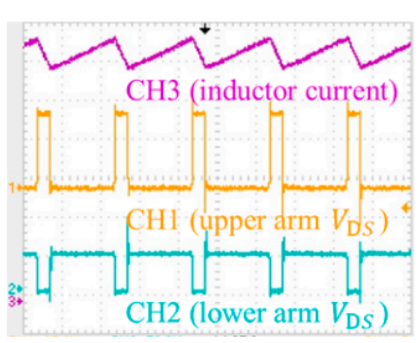

(b)

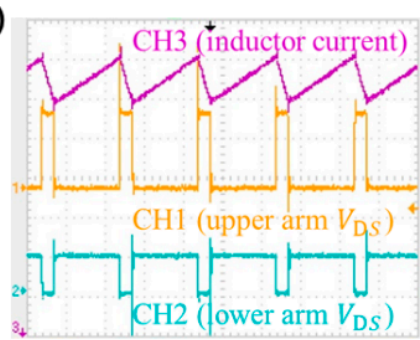

Figure 12. Experimental waveform of prototype DC-DC converter under boost mode. (CH1: $25 \mathrm{~V} /$ div, CH2: $50 \mathrm{~V} /$ div, CH3: 5 A/div, t: 25 us/div); (a) $1000 \mathrm{~W}$ (b) $2000 \mathrm{~W}$. 
(a)

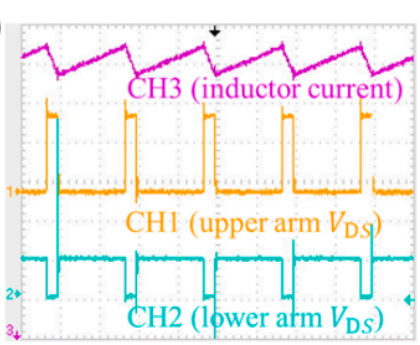

(b)



Figure 13. Experimental waveform of prototype DC-DC converter under buck mode. (CH1: $25 \mathrm{~V} / \mathrm{div}$, CH2: 50 V/div, CH3: 5 A/div, t: 25 us/div). (a) $1000 \mathrm{~W}$ (b) $2000 \mathrm{~W}$.

Table 3. Efficiency measurements of circuit operation.

\begin{tabular}{ccccccc}
\hline $\mathbf{V}_{\text {in }}$ & $\mathbf{I}_{\text {in }}$ & $\mathbf{V}_{\text {out }}$ & $\mathbf{I}_{\text {out }}$ & $\begin{array}{c}\text { Input Power (watt) } \\
\text { Boost mode }\end{array}$ & Output Power (watt) & Eff. \\
\hline \multicolumn{7}{c}{} \\
\hline 38 & 15.1 & 52.4 & 10.4 & 574.9 & 544.6 & $94.7 \%$ \\
38 & 30.0 & 51.3 & 20.8 & 1140.8 & 1066.2 & $93.5 \%$ \\
38 & 55.0 & 49.9 & 38.2 & 2090.8 & 1903.9 & $91.1 \%$ \\
\hline & & & & Buck mode & & \\
\hline 48 & 10.1 & 37.3 & 12.5 & 482.4 & 464.5 & $96.3 \%$ \\
48 & 25.3 & 38.7 & 30.0 & 1213.4 & 1160.7 & $95.7 \%$ \\
48 & 45.1 & 38.8 & 52.4 & 2162.9 & 2031.0 & $93.9 \%$ \\
\hline
\end{tabular}

\section{Conclusions}

This paper demonstrated a C-rate control method for a battery/SC HESS. With this method, the HESS is able to supply sufficient power for EV startup and acceleration, which is capable of preventing the battery from further degradation caused by the effects of frequent and rapid discharging by dynamic movements of EVs. A PWM control method associated with a current-sensing scheme was also developed to further simplify the required SC and load current sensors. The proposed method was first verified by simulation software where the proposed HESS can reduce the battery life loss by $2.34 \%$ a year and the battery lifespan was estimated to extend by around 1.5 years. Then, the experimental results also validated the effectiveness of the HESS incorporated with a $2 \mathrm{~kW}$ motor drive system. It was shown that the HESS can achieve high-efficiency operations in the boost and buck modes. With the converter only operating in acceleration, braking, and conditions with a required current more than the prescribed battery current limit, the loss in converter operation can be reduced and the overall efficiency can be further enhanced without additional cost and complexity.

Author Contributions: Conceptualization, M.-F.H. and F.-S.P.; methodology, M.-F.H.; software, R.Y.W.; validation, P.-H.C. and R.-Y.W.; formal analysis, P.-H.C.; investigation, P.-H.C.; resources, F.-S.P.; data curation, P.-H.C.; writing - original draft preparation, M.-F.H. and P.-H.C.; writing-review and editing, M.-F.H. and F.-S.P.; visualization, R.-Y.W.; supervision, F.-S.P.; project administration, F.-S.P.; funding acquisition, F.-S.P. All authors have read and agreed to the published version of the manuscript.

Funding: This work was supported by the Ministry of Science and Technology, Taiwan, under project MOST 109-2622-8-006-005 and 109-2622-E-024-005.

Institutional Review Board Statement: Not applicable.

Informed Consent Statement: Not applicable.

Data Availability Statement: The data presented in this study are available on request from the corresponding author. 
Acknowledgments: The authors are greatly indebted to the Electric Motor Technology Research Center of National Cheng Kung University for providing their valuable operating experience.

Conflicts of Interest: The authors declare no conflict of interest.

\section{References}

1. Broussely, M.; Biensan, P.; Bonhomme, F.; Blanchard, P.; Herreyre, S.; Nechev, K.; Staniewicz, R.J. Main aging mechanisms in Li ion batteries. J. Power Sources 2005, 146, 90-96. [CrossRef]

2. Vetter, J.; Novak, P.; Wagner, M.R.; Veit, C.; Moller, K.C.; Besenhard, J.O.; Winter, M.; Wohlfahrt-Mehrens, M.; Vogler, C.; Hammouche, A. Ageing mechanisms in lithium-ion batteries. J. Power Sources 2005, 147, 269-281. [CrossRef]

3. Nagpure, S.C.; Bhushan, B. Nanomaterials for electrical energy storage devices. In Encyclopedia of Nanotechnology; Springer: Dordrecht, The Netherlands, 2016; pp. 2473-2485.

4. Saleem, A.M.; Desmaris, V.; Enoksson, P. Performance enhancement of carbon nanomaterials for supercapacitors. J. Nanomater. 2016, 2016, 1537269. [CrossRef]

5. Gao, L.; Dougal, R.A.; Liu, S. Power enhancement of an actively controlled battery/ultracapacitor hybrid. IEEE Trans. Power Electron. 2005, 20, 236-243. [CrossRef]

6. Cao, J.; Emadi, A. A new battery/ultracapacitor hybrid energy storage system for electric, hybrid, and plug-in hybrid electric vehicles. IEEE Trans. Power Electron. 2012, 27, 122-132.

7. Han, X.B.; Ouyang, M.G.; Lu, L.G.; Li, J.Q. Cycle life of commercial lithium-ion batteries with lithium titanium oxide anodes in electric vehicles. Energies 2014, 7, 4895-4909. [CrossRef]

8. Shen, J.; Dusmez, S.; Khaligh, A. Optimization of sizing and battery cycle life in battery/ultracapacitor hybrid energy storage systems for electric vehicle applications. IEEE Trans. Industr. Inform. 2014, 10, 2112-2121. [CrossRef]

9. Rotenberg, D.; Vahidi, A.; Kolmanovsky, I. Ultracapacitor assisted powertrains: Modeling, control, sizing, and the impact on fuel economy. IEEE Trans. Control Syst. Technol. 2011, 19, 576-589. [CrossRef]

10. Zhang, L.; Hu, X.; Wang, Z.; Sun, F.; Deng, J.; Dorrell, D.G. Multiobjective optimal sizing of hybrid energy storage system for electric vehicles. IEEE Trans. Veh. Technol. 2018, 67, 1027-1035. [CrossRef]

11. Eldeeb, H.H.; Elsayed, A.T.; Lashway, C.R.; Mohammed, O. Hybrid energy storage sizing and power splitting optimization for plug-in electric vehicles. IEEE Trans. Ind. Appl. 2019, 55, 2252-2262. [CrossRef]

12. Asensio, M.; Magallan, G.A.; Amaya, E.G.; De Angelo, C.H. Efficiency and performance analysis of battery-ultracapacitor based semi-active hybrid energy systems for electric vehicles. IEEE Lat. Am. Trans. 2018, 16, 2581-2590. [CrossRef]

13. Naseri, F.; Farjah, E.; Ghanbari, T. An efficient regenerative braking system based on battery/supercapacitor for electric, hybrid, and plug-in hybrid electric vehicles with BLDC motor. IEEE Trans. Veh. Technol. 2017, 66, 3724-3738. [CrossRef]

14. Manandhar, U.; Tummuru, N.R.; Kollimalla, S.K.; Ukil, A.; Beng, G.H.; Chaudhari, K. Validation of faster joint control strategy for battery- and supercapacitor-based energy storage system. IEEE Trans. Ind. Electron. 2018, 65, 3286-3295. [CrossRef]

15. Hredzak, B.; Agelidis, V.G. Model predictive control of a hybrid battery-ultracapacitor power source. In Proceedings of the 7th International Power Electronics and Motion Control Conference, Harbin, China, 2-5 June 2012; pp. $2294-2299$.

16. Hredzak, B.; Agelidis, V.G.; Jang, M. A model predictive control system for a hybrid battery-ultracapacitor power source. IEEE Trans. Power Electron. 2014, 29, 1469-1479. [CrossRef]

17. Pai, F.S.; Huang, S.J. A novel design of line-interactive uninterruptible power supplies without load current sensors. IEEE Trans. Power Electron. 2006, 21, 202-210.

18. Jing, W.L.; Lai, C.H.; Wong, S.H.W.; Wong, M.L.D. Battery-supercapacitor hybrid energy storage system in standalone DC microgrids: A review. IET Renew. Power Gener. 2017, 11, 461-469. [CrossRef]

19. Grbovic, P.J.; Delarue, P.; Moigne, P.L.; Bartholomeus, P. A three-terminal ultracapacitor-based energy storage and PFC device for regenerative controlled electric drives. IEEE Trans. Ind. Electron. 2012, 59, 301-316. [CrossRef]

20. Hwang, J.J.; Chen, Y.J.; Kuo, J.K. The study on the power management system in a fuel cell hybrid vehicle. Int. J. Hydrogen Energy 2012, 37, 4476-4489. [CrossRef]

21. Hung, Y.H.; Wu, C.H. A combined optimal sizing and energy management approach for hybrid in-wheel motors of EVs. Appl. Energy 2015, 139, 260-271. [CrossRef]

22. Hsieh, M.F.; Weng, Y.C. A low torque ripple direct torque control method for interior permanent magnet motor. Appl. Sci. 2020, 10, 1723. [CrossRef] 